\title{
NIH seeks funding for neuroscience centre ...
}

Washington

Officials at the US National Institutes of Health (NIH) are hoping that President Bill Clinton's 2001 budget request will include funding for work to begin on a \$270-million neuroscience research centre.

Construction of the centre, to be located on the NIH campus in Bethesda, Maryland, would start with a 20,000 square metre building costing \$70-90 million. This would be followed by additions and renovations to an existing building.

Gerald Fischbach, director of the National Institute of Neurological Disorders and Stroke, and Steven Hyman, director of the National Institute of Mental Health, have been discussing bringing together NIH intramural neuroscience research into a single building over the past year.

Only recently has the need for a new facility been agreed, however. Former NIH director Harold Varmus expressed his support for the project at his final advisory committee meeting last month, and the White House is expected to be sympathetic to the request.

Fischbach and Hyman decline to say how much money they are seeking for the project's first year until Clinton's 2001 budget request is released next month. Congressional approval would be needed for the construction project, which is likely to take about eight years to complete.

One reason Fischbach and Hyman want to build the centre is to help reverse the fragmentation that has occurred as neuroscience and brain research have evolved at various NIH institutes. "You don't want the research to suffer because it's been fragmented," says Fischbach.

He points out, for example, that changes in the activity of neurotransmitters such as dopamine are likely to contribute to schizophrenia, Parkinson's disease, drug addiction and chronic pain - each of which is currently studied at a different institute.

After neuroscientists are moved from nine separate institutes (including two that are off-campus) into a single complex, research should be reorganized by themes to promote projects ranging from basic to clinical research, Fischbach says. He cites neurodegeneration, neurogenetics and pain as possible themes.

Hyman agrees that combining various approaches will help bridge basic and clinical science. Creating the complex near the NIH's Clinical Research Centre, a \$333 million building scheduled for completion in 2002 , should further that goal, he adds.

"It makes sense to physically unify the research on campus, in order to have proximity to the critical mass of molecular biology and genetics research on the one hand, and to be near the new clinical research centre on the other," Hyman says.

The new building will also be highly flexible, Fischbach and Hyman say, with moveable walls, lab benches that can be adjusted for both in vitro and animal work, and space for imaging equipment that scientists from the multiple institutes can share. Sharing research equipment and reducing duplication should cut costs, they add.

Dennis Choi, president of the Society for Neuroscience and a neurologist at the Washington University school of medicine in St Louis, Missouri, says he is "enthusiastic" about the proposal and agrees that it could promote greater efficiency. The complex should bring together basic and clinical neuroscience, he says: "There's a lot happening at that intersection."

Beyond the arguments of unity, economy and synergy, Joseph Coyle, chairman of psychiatry at Harvard Medical School, says the project can be justified by the direction in which neuroscience appears to be heading.

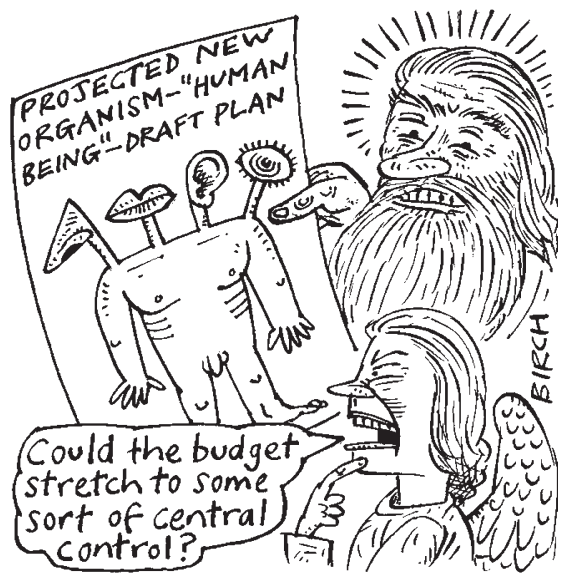

Once the human genome has been sequenced, "the real focus is going to be on how the genome constructs the brain," says Coyle, pointing out that more than half the human genome is likely to be related to the brain or nervous system. "Scientifically, there really is a good reason for getting the centre together."

Paul Smaglik

\section{... as lobbyists anticipate more money for all}

\section{Washington}

US President Bill Clinton is expected to seek substantial increases in funding for basic scientific research in his budget request for the 2001 financial year, to be released on 7 February.

Science lobbyists say the request may include $\$ 1$ billion (6 per cent) more for the National Institutes of Health (NIH) and a "double-digit increase" (at least $\$ 350$ million) for the National Science Foundation (NSF) - the largest increase that Clinton has requested for the agency in his eight years in office.

Clinton is expected to announce a broad effort to boost spending on scientific research in his State of the Union address on 27 January. Other important science-funding agencies, including the space agency NASA, the Department of Energy and the Department of Defense, are also expected to benefit.

Some of the new money will be allocated to targeted initiatives in computer research, nanotechnology and environmental science. But the president also intends to propose substantial increases in funding for basic research in most scientific disciplines.

Unlike similar increases he proposed two years ago, these are not expected to be conditional on a tobacco tax or any similar budgetary gimmick. However, they will exceed the spending caps agreed by Congress and the White House in 1997. The caps were massively breached during last year's budget negotiations, but have not yet been formally abandoned.

Clinton will propose substantial additional funding for the NSF to continue a research initiative in information technology begun last year, to lead an interagency nanotechnology initiative, which will be unveiled in the budget (see Nature 400, 95; 1999), and to start a build-up of research in the environmental sciences that was proposed last autumn by the National Science Board (see Nature 400, 492; 1999).

Michael Lubell, head of public affairs at the American Physical Society, welcomed reports of the budget proposal, saying it reflects recent calls by a coalition of scientific societies for a "balanced portfolio" of research spending.

But John Porter (Republican, Illinois), chair of the appropriations subcommittee in the House of Representatives that funds the NIH, said he was "disappointed" with the president's reported plan to propose a \$1 billion increase for the NIH. Porter points out that it "falls short" of a hoped-for 15 per cent increase, which would double the agency's budget in five years. He adds that the president failed to support doubling NIH funds during early stages of the budget process in the past two years. Congress gave the agency increases of 15 per cent or more in 1999 and 2000, which the president ultimately approved.

Ray Merenstein, vicepresident of Research!America, a lobby group for biomedical research, agrees that the proposed increase for the NIH is "not high enough". But he is optimistic about the outcome, as the president's initial offer is still one of the highest percentage increases Clinton has proposed for the agency since taking office.

Colin Macilwain \& Paul Smaglik 